\title{
BIOLOGY AND PREDATION EFFICIENCY OF THE SPIDER SPECIES STEATODA ALBOMACULATA (DE GEER,1778) (ARANEIDA: THERIDIIDAE) FEEDING ON THE THREE DIFFERENT PREYS
}

\author{
AML H. M. ROMEIH ${ }^{1}$, M. H. EL- ERKOUSOUSY ${ }^{2}$ AND A. K. AIAD ${ }^{2}$ \\ 1. Agric. Zoology Dept., Fac. Agric. Cairo University, Giza \\ 2. Plant Protection Research Institute, ARC, Dokki, Giza
}

(Manuscript received 4 March 2009)

\begin{abstract}
The spider Steatoda albomaculata (De Geer) was reared on three different types of prey i.e. motile stages of the two spotted spider mite, Tetranychus urticae Koch,the cotton aphid,Aphis gossypii (Glover) and first and second larval instars of the cotton leafworm,Spodoptera littoralis (Boisd.). Incubation period averaged 10 days for both male and female. They pass through three spiderlings before reaching adult. The life cycle averaged (48.4\&36.8), (39.8\&33.7) and (33.1\&27.1) days for female and male when fed on the three above mentioned prey, respectively at $27 \pm 2 c^{\circ}$ and $70 \pm 5 \%$ R.H.Female oviposition period durated 15.9, 14.7 and 12.7 days and the deposited egg sacs averaged 2.8, 3.2 and 3.1 when fed on $T$. urticae, $A$. gossypii and $S$. littoralis, respectively. Total number of prey consumed averaged 329.7 \& 344.6, 191.5\&295.0 and $194.9 \& 293.0$ of the aforementioned prey individuals for spider female and male, respectively through its life span.
\end{abstract}

\section{INTRODUCTION}

Spiders are cosmopolitan that live in many ecological environments. as predators, they play a considerable role in agroecosystem as biocontrol agents (Levy, 1998).

Members of family Theridiidae are small to medium size. They are usually found hanging upside down in an irregular web suspended on plants or hidden in rock crevices or fissures in soils (Levy,1998 and ElErksousy,2000). Many of them use very fine threads often hard to be noticed unless occasionally glitter in the sun light or covered with dust (Levy and Amitai, 1981).

In Egypt, some species of this family were usually found in different field and truck crops and orchards. Due to its spread and importance ElErksousy, 2003, El-Erksousy et al., 2006 and Hussein et al.,2003 studied the biology of three species of this family.The present work throw light on biological aspects and predation efficiency of the spider Steatoda albomaculata (DE GEER,1778) as a common species in different localties. 


\section{MATERIALS AND METHODES}

\section{Rearing technique}

S. albomaculata individuals were collected from maize fields in Ismailia governorate by using sweeping or directly from maize plants.Identification took place in the laboratory by helping of sterioscopicbinoclar using taxonomic key Jones, 1983. Newly emerged adult female and male were confined together in a test tube $(20 \mathrm{~cm}$ long and $0.5 \mathrm{~cm}$ in diameter), closed with cotton pad and supplied daily with prey. The female was noticed daily until laying the egg sac and hatched spiderlings. Each spiderling was isolated separately in a test tube together with surplus numbers of prey individuals and noticed till reaching adult stage.

The three types of prey, moving stages of the two-spotted spider mite, Tetranychus urticae Koch,the cotton aphid, Aphis gossypii (Glover) and $1^{\text {st }}$ and $2^{\text {nd }}$ larval instars of the cotton leafworm, Spodoptera littoralis (Boisd.) were used as food through the life span of the true spider. The numbers of consumed prey individuals were recorded daily and replaced by fresh ones. Behaviour and some biological aspects were also recorded.

Experiment was carried out under laboratory conditions $\left(27 \pm 2^{\circ} \mathrm{C}\right.$ and $70 \pm 5$ R.H.\%).

\section{RESULTS AND DISCUSSION}

\section{Feeding behavior}

When the predator $S$. albomaculata notice the prey, it usually comes close and moves around it for few seconds, then catches it between its chelicerae by the help of the front legs. Embeding its chelicerae in the prey,the predator starts to suck prey contents till leaving it as exuvium. The predator abdomen becomes enlarged and usually rests for few minutes before searching again for another one. No differences in feeding behavior were noticed when spider fed on the three tested prey.

\section{Mating behavior}

\section{1- Preparing period}

The virgin female stayed for about 5 days as a premating period. The male was firstly placed in the test tube and then followed by the female. The latter started to come close to the male in relative movements for about 2 minutes. The male came close to it, moving his front legs up and down and 
pedipalps alternatively. it then touched the tips of the female legs and pidipalps, before the beginning of copulation.Both sexes must pass through the preparing period before copulation occurs. otherwise,the female refuses the male, threatening by its chelicerae to enforce male to move away.

\section{2- Copulation}

The male holds the female using its first pair of legs, leg I to hold her leg II, and his leg II to hold her leg III. it then inserts his right palp into the female genital opening. The sperms are transferred in female seminal receptacles. The mating process continued for about 1-2 minutes, then the male escaped away.

\section{Oviposition and incubation period}

The gravid female of $S$. albomaculata deposited 2-3 egg sacs during its oviposition period. Each sac contained about 21 eggs. The egg sac is white yellowish measures $2 \mathrm{~cm}$ in long and $0.9 \mathrm{~cm}$ wide. The incubation period averaged 10.0 days for both male and female.

\section{Development and adult longevity}

Each female and male passes through three spiderlings before reaching adult.However, this number differs according to species as S.triangulosa(Walkenear) has five spiderlings when fed on the $1^{\text {st }}$ larval stage of the pink bollworm,Pectinophora gossyiella (Saund) El-Erksousy and Amer 2007, while Anelosimus aulicus (koch) of the same family(Therdiidae) has five spiderlings when fed on aphids,Aphis craccivora (Hussein et al., 2003), Theridion egyptium (Koch) has only two spiderlings when fed on the two spotted spider mite T.urticae .(El-erksousy,2003).When tested spider feeding on the two spotted spider mite $T$. urticae moving stages, $A$. gossypii and $S$. littoralis $1^{\text {st }}$ and $2^{\text {nd }}$ instar larvae, the average female $S$. albomaculata $1^{\text {st }}$ spiderling durated $8.7,6.6$ and 4.9 days, the $2^{\text {nd }}$ spiderling durated $18.8,15.9$ and 11.3 days and the $3^{\text {rd }}$ spiderling durated $10.9,7.3$ and 6.9 days with total immatures 38.4, 29.8 and 23.1 days, respectively(Table 1).This means that cotton leaf worm accelerated development followed by cotton aphid then the two spotted spider mite.Also the duration of the second spiderling was nearly twice as that of the $1^{\text {st }}$ and $3^{\text {rd }}$ spiderling. Adding 10.0 days incubation period the female life cycle durated 48.4, 39.8 and 33.1 days,respectively.(Table 1) Male followed similar trend as female. Female longevity averaged 48.7, 41.7 and 37.3 days.(Table 1 ) when fed on $1^{\text {st }}$ and $2^{\text {nd }}$ instar larvae of S.littoralis ,A.gossypii and moving stages of spider mite T.urticae, respectively.Statistical analysis proved that the duration of female life cycle and adult longevity were 
significantly shorter when fed on the cotton leaf worm larvae than on the two spotted spider mite.

After pre-oviposition period female stopped feeding about two days and began to web the egg sac by its spinnertes, then laid all eggs in the same day and covered it with a layer of dense silky webs. The spider female laid on average of $2.8,3.2$ and 3.1 egg sacs, each containing average of 21.3, 20.0 and 21.8 eggs, when fed on T.urticae, ,A.gossypiänd S.littoralis respectively (Table 2 ).

When female of Anelosimus aulicus(Koch) of family theridiidae was feeding on Aphis, Aphis craccivora,passes through five spiderlings and laid an average of 8.6 egg-sacs (Hussein et al .,2003)

Putman (1967) described the life cycle of Philodromus praelustris Keyserling (Family: Philodromidae). Females produced up to 12 egg sacs containing a total of over 299 eggs in insectory, but the later eggs did not hatch.

During the oviposition period, the females deposited $6.3 \mathrm{sac} / \mathrm{female}$, each egg-sac contained about 31.1 eggs, the incubation period was 16 days. The spider females passed life cycle and life span longer than males. Also, the females consumed individuals of prey higher than males during life cycle and life span.

\section{Food consumption}

Data presented in Table (3) showed that $1^{\text {st }}, 2^{\text {nd }}$ and $3^{\text {rd }}$ spiderlings of the spider $S$. albomaculata female fed on $40.1,113.9$ and 90.7 individuals of T. urticae or $31.6,39.2$ and 36.0 individuals of $A$. gossypii or $30.5,38.3$ and 35.0 of $1^{\text {st }}$ instar larvae of $S$. littoralis, respectively. Male spiderlings followed similar trend but with relatively lower numbers of these prey. During adult female longevity, the spider consumed 135, 84.5 and 81.1 individuals of $T$. urticae, $A$. gossypii and $S$. littoralis, respectively, while those averaged 141.6, 81.23 and 78.22 individuals for male, respectively. This proved that the second spiderling fed on the greatest total number of prey due to its longest period.

Finally, it can be concluded that,the spider S.albomaculata fed and developed successively on the three tested prey, yet $1^{\text {st }} \& 2^{\text {nd }}$ instar larvae of the cotton leafworm considered the most suitable prey, as it accelerated predator development, relatively increasing female productively and predation capacity. 
Table 1. Duration of developmental stages of Steatoda albomaculata when fed on Tetranychus urticae, Aphis gossypii and Spodoptera littoralis under laboratory condition $\left(27 \pm 2^{\circ} \mathrm{C}\right.$ and $70 \pm 5 \%$ R.H. $)$.

\begin{tabular}{|c|c|c|c|c|}
\hline \multirow{2}{*}{ Spider stages } & \multirow{2}{*}{ Sex } & \multicolumn{3}{|c|}{ Average duration in days } \\
\hline & & T. urticae & A. gossypii & S. littoralis \\
\hline Incubation period & - & $10.0 \pm 0.82$ & $10.0 \pm 0.82$ & $10.0 \pm 0.82$ \\
\hline \multirow{2}{*}{$1^{\text {st }}$ spiderling } & 오 & $8.7 \pm 0.48$ & $6.6 \pm 0.96$ & $4.9 \pm 1.37$ \\
\hline & $\hat{0}$ & $8.3 \pm 0.48$ & $6.7 \pm 0.94$ & $4.4 \pm 1.07$ \\
\hline \multirow{2}{*}{$2^{\text {nd }}$ spiderling } & q & $18.8 \pm 2.66$ & $15.9 \pm 2.99$ & $11.3 \pm 2.11$ \\
\hline & $\hat{0}$ & $11.5 \pm 0.52$ & $10.4 \pm 1.07$ & $7.1 \pm 1.20$ \\
\hline \multirow{2}{*}{$3^{\text {rd }}$ spiderling } & 우 & $10.9 \pm 1.20$ & $7.3 \pm 1.33$ & $6.9 \pm 1.66$ \\
\hline & $\hat{0}$ & $7.0 \pm 1.20$ & $6.6 \pm 0.97$ & $5.6 \pm 1.17$ \\
\hline \multirow{2}{*}{ Total spiderlings } & 우 & $38.4 \pm 4.34$ & $29.8 \pm 3.05$ & $23.1 \pm 4.09$ \\
\hline & $\hat{0}$ & $26.8 \pm 2.2$ & $23.7 \pm 1.88$ & $17.1 \pm 2.02$ \\
\hline \multirow{2}{*}{ Life cycle } & 우 & $48.4 \pm 4.34^{\mathrm{a}}$ & $39.8 \pm 3.08^{d}$ & $33.1 \pm 3.90^{c}$ \\
\hline & 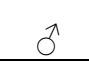 & $36.8 \pm 2.38^{\mathrm{b}}$ & $33.7 \pm 2.26^{c}$ & $27.1 \pm 2.18^{\mathrm{e}}$ \\
\hline \multirow{2}{*}{ Longevity } & 오 & $48.7 \pm 13.82^{\mathrm{a}}$ & $41.7 \pm 10.15^{\mathrm{b}}$ & $37.3 \pm 6.47^{c}$ \\
\hline & 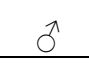 & $34.4 \pm 3.65^{b}$ & $35.1 \pm 3.87^{\mathrm{a}}$ & $33.2 \pm 3.32^{c}$ \\
\hline \multirow{2}{*}{ Life span } & 오 & $97.1 \pm 15.88$ & $81.5 \pm 10.82$ & $70.4 \pm 8.60$ \\
\hline & $\hat{0}$ & $71.2 \pm 3.30$ & $68.8 \pm 2.78$ & $60.3 \pm 2.58$ \\
\hline
\end{tabular}

LSD $_{0.05}$

$\begin{array}{lcc}\text { For longivity } & + & 1.19 \\ & 0 & 0.52 \\ \text { For life cycle } & + & 7.28 \\ & + & 0.84\end{array}$

Table 2. Longevity and fecundity of Steatoda albomaculata female when fed on Tetranychus urticae, Aphis gossypii and Spodoptera littoralis under laboratory condition $\left(27 \pm 2^{\circ} \mathrm{C}\right.$ and $70 \pm 5 \%$ R.H. $)$.

\begin{tabular}{|c|c|c|c|c|c|}
\hline \multirow{2}{*}{ prey } & \multicolumn{3}{|c|}{ Average period in days } & \multicolumn{2}{c|}{ Fecundity } \\
\cline { 2 - 6 } & $\begin{array}{c}\text { Pre- } \\
\text { oviposition }\end{array}$ & Oviposition & $\begin{array}{c}\text { Post- } \\
\text { oviposition }\end{array}$ & $\begin{array}{c}\text { No. of egg } \\
\text { sacs/ } \\
\text { female }\end{array}$ & $\begin{array}{c}\text { No. of } \\
\text { eggs/sac }\end{array}$ \\
\hline T. urticae & $13 \pm 0.82$ & $15.9 \pm 0.88$ & $19.8 \pm 2.86$ & $2.8 \pm 0.84^{\mathrm{a}}$ & $21.3 \pm 0.47$ \\
\hline A. gossypii & $11.6 \pm 0.66$ & $14.7 \pm 0.78$ & $15.4 \pm 3.2$ & $3.2 \pm 0.74^{\mathrm{a}}$ & $20.0 \pm 1.95$ \\
\hline S. littoralis & $10.4 \pm 0.92$ & $12.7 \pm 0.9$ & $14.2 \pm 2.27$ & $3.1 \pm 0.83^{\mathrm{a}}$ & $21.8 \pm 2.27$ \\
\hline
\end{tabular}

LSD 0.05

For No. of egg sacs $=0.96$ 
Table 3. Food consumption of Steatoda albomaculata when fed on Tetranychus urticae, Aphis gossypii and Spodoptera littoralis stages at $27 \pm 2^{\circ} \mathrm{C}$ and $70 \pm 5 \%$ R.H.

\begin{tabular}{|c|c|c|c|c|}
\hline \multirow{2}{*}{ Spider stages } & \multirow{2}{*}{ Sex } & \multicolumn{3}{|c|}{ No. of devoured prey individuals } \\
\hline & & T. urticae & A. gossypii & S. littoralis \\
\hline \multirow{2}{*}{$1^{\text {st }}$ spiderling } & 오 & $40.1 \pm 4.9$ & $31.6 \pm 4.10$ & $30.5 \pm 1.43$ \\
\hline & $0^{\pi}$ & $40.7 \pm 3.9$ & $30.6 \pm 2.11$ & $28.7 \pm 1.41$ \\
\hline \multirow{2}{*}{$2^{\text {nd }}$ spiderling } & q & $113.9 \pm 23.4$ & $39.2 \pm 1.6$ & $38.3 \pm 1.1$ \\
\hline & $0^{\lambda}$ & $110.7 \pm 23.7$ & $32.5 \pm 1.96$ & $30.2 \pm 2.52$ \\
\hline \multirow{2}{*}{$3^{\text {rd }}$ spiderling } & q & $90.7 \pm 20.9$ & $36 \pm 1.41$ & $35 \pm 1.41$ \\
\hline & $\pi$ & $112.2 \pm 21.4$ & $36.6 \pm 1.8$ & $29.6 \pm 1.8$ \\
\hline \multirow{2}{*}{ Total immature } & q & $244.7 \pm 3.94^{\mathrm{a}}$ & $106.8 \pm 7.11^{\mathrm{b}}$ & $103.8 \pm 49.2^{\mathrm{b}}$ \\
\hline & $\sigma^{\lambda}$ & $263.6 \pm 5.73^{\mathrm{a}}$ & $99.7 \pm 5.87^{b}$ & $88.5 \pm 49.00^{c}$ \\
\hline \multirow{2}{*}{ Longevity } & 우 & $135.00 \pm 1.00^{\mathrm{a}}$ & $84.5 \pm 8.35^{\mathrm{b}}$ & $81.1 \pm 8.11^{\mathrm{c}}$ \\
\hline & o & $141.6 \pm 1.53^{\mathrm{a}}$ & $81.23 \pm 5.41^{b}$ & $78.22 \pm 4.87^{c}$ \\
\hline \multirow{2}{*}{ Life span } & q & $329.7 \pm 58.9$ & $191.5 \pm 11.50$ & $184.9 \pm 41.14$ \\
\hline & $\hat{0}$ & $344.6 \pm 49.0$ & $295.0 \pm 24.29$ & $293.0 \pm 20.36$ \\
\hline
\end{tabular}

$\operatorname{LSD}_{0.05}$

\begin{tabular}{|c|c|}
\hline ForTotal immature $=$ & \\
\hline For Longevity = & \\
\hline
\end{tabular}

Statistical analysis revealed that, there are non significant difference between the total immature stages which consumed on A.gossypii and S.litoralis and high significant difference between the previous and which consumed on T.urticae. where LSD $=5.62$ and 1.21, for female and male, respectively, also highly significant difference for adult longevity in females and males, where LSD $=1.73$ and 1.65 respectively, (Table, 3 ).

El-Erksousy et al., (2003) found that spiders Theridion egyptium when fed on $T$. urticae at $26^{\circ} \mathrm{C}$ and $60-70$ R.H.\% the life cycle averaged $43.1,42.1$ days for female and male, respectively. Dinter (2004) reared Erigone atra (Blackwall) (Araneae: Linyphiidae) within a few days females started to produce egg-sacs. The mean rearing success (from 1 to 2 -day-old spiderlings to adults) was 59.3\%. After 3-5 weeks most of the spiderlings developed to adults. Within a few days females started to produce egg-sacs. 


\section{REFERENCES}

1. Dick, Jones. 1983. The country life guide to spider of pertain and nourthren Europe . country life books $320 \mathrm{pp}$

2. Dinter, A. 2004. A mass rearing method for the linyphiid spider species Erigone atra (Blackwall) (Araneae: Linyphiidae). J. Appl. Entomol., 128 (3): 200-203.

3. El-Erksousy, M. H. 2000. Studied on some true spider in Egypt .Ph.D. Thesis, Fac. Agric., Al-Azhar Univ. 130 pp.

4. El-Erksousy, M. H. 2003. Biology of the spider Theridion egyptium Fawzy \& ElErksousy fed on Spodoptera littoralis larvae. Bull. Ent. Soc. Egypt, 80:229-233.

5. El-Erksousy, M. H. and R. M. Amer. 2007. Biological and predation studies on the predaceous spider, Steatoda triangulosa (Walckenaer) fed on the pink bollworm, Pectinophora gossypiella (Saund.). Egypt, J. Agric. Res., 85 (5): 1599-1611.

6. El-Erksousy, M. H., M. Shoeib, Ameira and Gomaa, O. Wafaa. 2006. Biological of the spider, Steatoda triangulosa (Walckenare) fed on larvae of Spodoptera littoralis (Boisd). $2^{\text {nd }}$ Conf., On Farm. I.P.M. 16-18. Jan., :256-259.

7. Hussein, A. M., M. F. Hassan and N. F. R. Ahmed. 2003. Biological aspects of Anelosimus aulicus (C.L. Koch, 1838) (Arachnida : Araneida : Theridiidae) in Egypt. Serket, 8 (4): 129-134.

8. Levy, G. 1998. Fauna Palestine. Arachnidae, Araneae: Theridiidae. The Israel academy of sciences and Humanities. 225 pp.

9. Levy, G. and P. Amitai. 1981. The spider genus Enoplogntha (Araneae : Theriidae) in Israel. Zool. J. Linn. Soc., 72:43-67.

10. Putman, W. L. (1967): Life histories and habits of two species of Phiodromus (Araneid : Philodromidae) in Ontario. Can. Entomol., 99: 622-631. 
STEATODA النواحي البيولوجية والسلوكية والقدرة الإفتراسية للعنكبوت ALBOMACULATA

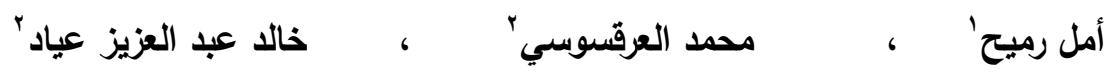

$$
\begin{aligned}
& \text { 1 - كلية الزراعة - جامعة القاهرة- الجبيزة }
\end{aligned}
$$

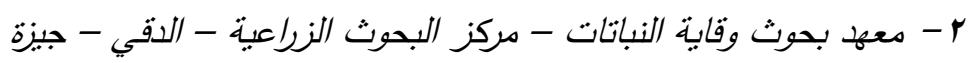

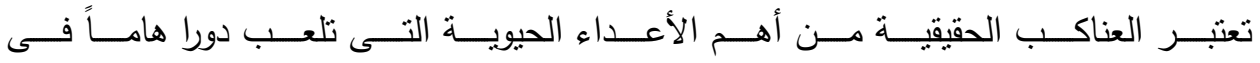

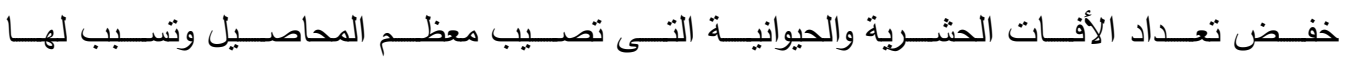

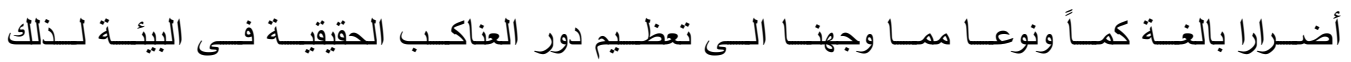

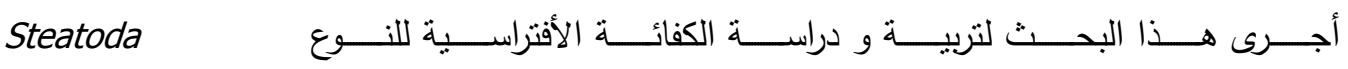

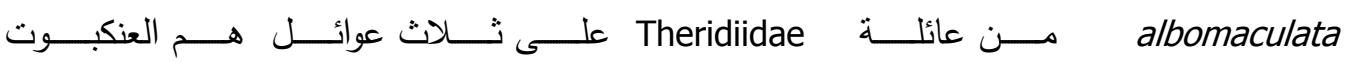

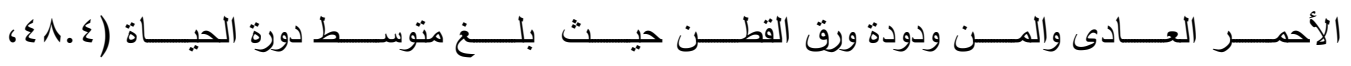

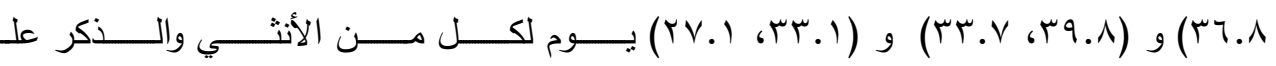

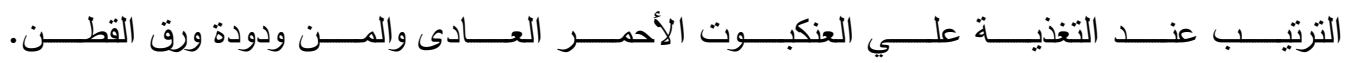

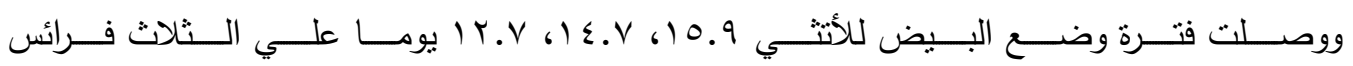

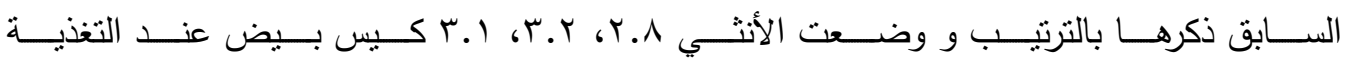

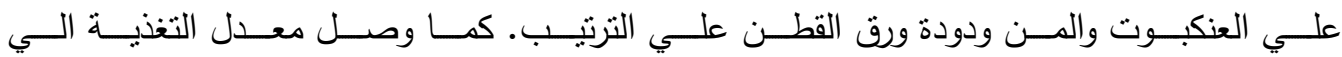

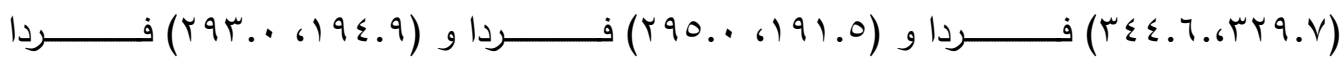

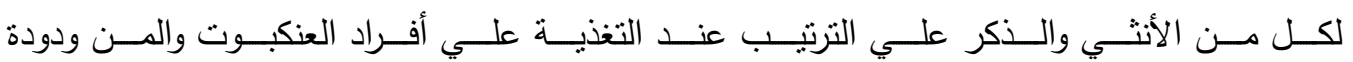

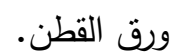

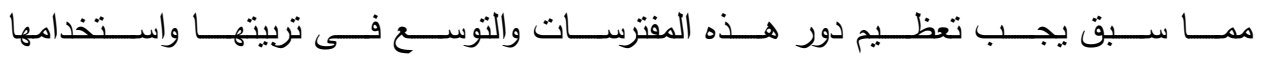

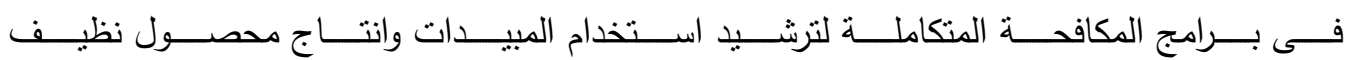
صالح للتصدير 